\title{
Photosynthetic responses and reproductive ability of strawberry following sunlight application in a plant factory closed system in subtropical Okinawa
}

\author{
L.T. Le ${ }^{1,2}$, H.T. Dinh ${ }^{3}$, H. Takaragawa ${ }^{1}$, K. Watanabe ${ }^{1}$, K. Ureshino ${ }^{1}$ and Y. Kawamitsu ${ }^{1}$ \\ ${ }^{1}$ Faculty of Agriculture, University of the Ryukyus, Okinawa, Japan \\ 2 The United Graduate School of Agricultural Science, Kagoshima University, Kagoshima, Japan \\ ${ }^{3}$ Faculty of Agronomy, Vietnam National University of Agriculture, Hanoi, Vietnam
}

\begin{abstract}
Summary
Sunlight is an abundant source of green energy that gives an energy-saving solution when introduced into a plant factory. However, a limitation point of applying sunlight is that it is unstable on cloudy and rainy days, and it fluctuates by seasons. Aiming to produce strawberry in subtropical areas, we investigated the effects of different light conditions on photosynthetic responses and reproductive ability of strawberry grown in a closed-type plant factory using sunlight (solar plant factory, SPF). The strawberries were grown under two different light conditions [full sunlight (S) or $10 \%$ sunlight + fluorescent light (SA)] with a $\mathrm{CO}_{2}$ concentration of $1,200 \mu \mathrm{mol} \mathrm{mol}{ }^{-1}$ and a relative humidity of $50 \% \pm 10 \%$. The results showed that under long-day conditions, the response of net photosynthetic rate $\left(P_{n}\right)$ of the strawberries leaves to different light levels did not differ between the two light conditions and was equal to that of plants grown in a $\mathrm{CO}_{2}$-enriched greenhouse. However, due to lower light intensity under short-day conditions, the response of $P_{n}$ of the plants was significantly reduced in $S$ treatment compared with that in SA treatment. Supplemented lighting to stabilize the light intensity showed effectiveness in improving $P_{n}$ under the short-day conditions. The strawberries grown in SPF showed a high potential to produce flowers and fruits, which were not inferior to those under other controlled environment productions. These results suggest that strawberry production using SPF in the subtropics is practicable, and the limitation of SPF can be overcome by additional lighting utilization.
\end{abstract}

Keywords

day length, light fluctuation, net photosynthetic rate, reproductive growth, solar plant factory (SPF), vegetative growth

\section{Introduction}

Strawberry (Fragaria $\times$ ananassa Duch.) is a fruit with high potential to promote human health (Giampieri et al., 2015), having high economic values, and commercially produced worldwide (Simpson, 2018). However, strawberry is a temperate plant species whose cultivation is restricted by regional climates, especially in the tropical and subtropical regions. Specifically, in Vietnam, the country is wholly located in the tropical climate zone; strawberry production

\section{Significance of this study}

What is already known on this subject?

- Strawberry is a temperate species, whose production is limited in tropical or subtropical regions.

- Solar plant factory (SPF) can be used for crop production in subtropical areas. However, sunlight utilized in SPF is unstable and is fluctuating season by season.

What are the new findings?

- Negative effects of sunlight fluctuation on strawberry growth in SPF could overcome by supplemented lighting. SPF is practicable for strawberry production in tropical or subtropical areas.

What is the expected impact on horticulture?

- To contribute to the improvement of cultivation methods for producing strawberry in the tropical and subtropical regions.

in the central and southern regions is almost impossible. In Vietnam, strawberries are mainly produced in the highland, the tropical monsoon climate area (Lam Dong province); nonetheless, most of field production areas are strongly damaged by pests and diseases that lead to increase utilization of plant protection chemicals and reduce fruit qualities (Lam Dong crop production and plant protection Sub Department, Vietnam, 2013, data not shown). Together with the regional climate limitation, pests and disease are also a further disadvantage in the tropics and subtropics against strawberry production. Therefore, to expand strawberry cultivation in the tropical and subtropical regions and to eradicate the utilization of plant protection chemicals, an effective production system is required.

In this situation, application of plant factory systems could be a potential cultivation method for strawberry production. A plant factory, known as plant factory using artificial light (PFAL), is a system used to grow plants under strictly controlled environments (Kozai, 2013), allowing the production of high-quality and pesticide-free crops (Nakamura and Shimizu, 2019). Moreover, to use sunlight advantageously in subtropics and to reduce energy consumption in PFAL, an "Okinawa-type plant factory" (in this study, we mentioned as solar plant factory, SPF) was developed basely on modification of a PFAL to apply sunlight as a lighting source. It was reported that introducing sunlight, utilization of LED light, 
and renewable energy in the SPF could reduce up to $30 \%$ of total energy consumption (Kawasaki et al., 2015; Ueno and Kawamitsu, 2017). This advantage could facilitate the application of SPF in tropical and subtropical areas. Hence, strawberry production in the SPF system could bring more advantages to its adoption to the tropical and subtropical climate conditions. However, there is a limitation that sunlight introduced into SPF is unstable on cloudy and rainy days and it fluctuates season by season.

Light factor is the driving force of plant growth through direct effects on photosynthesis process. Under different lighting conditions, plants exhibit different levels of photosynthesis. Photosynthetic rate $\left(\mathrm{P}_{\mathrm{n}}\right)$ of leaves reflects the physiological and biochemical conditions of plants in responding to environmental conditions (Upmeyer and Koller, 1972; Carlen et al., 2009). The $\mathrm{P}_{\mathrm{n}}$ closely relates to the fruit productivity of strawberry (Choi et al., 2016; Goto et al., 2018; Hidaka et al., 2016). Smeets (1980) demonstrated that reproductive growth characteristics, including earlier flowering, flower numbers, the percentage of fruit set, and fruit numbers of strawberry, were increased by the enhanced $P_{n}$ from the supplemental lighting conditions. Therefore, photosynthetic responses and reproductive traits of plants could be used as the parameters to evaluate the light effectiveness for strawberry cultivation in a plant factory.

With the target of applying SPF in Vietnam for strawberry production in the future, we continue to study to overcome the above-mentioned disadvantage of the SPF developed in Okinawa. In this study, the limitation of sunlight introduced into SPF was investigated based on photosynthetic responses and reproductive ability of strawberries grown under different sunlight application conditions.

\section{Materials and methods}

\section{Plant materials and growth conditions}

The June-bearing strawberry cultivar 'Sachinoka' was used in this study. Strawberry plantlets sourced from tissue culture were first acclimatized to the plant factory conditions for 30 days and were then grown hydroponically in a SPF located in Nakagusuku, Okinawa, Japan $\left(26^{\circ} 15^{\prime} \mathrm{N}, 127^{\circ} 47^{\prime} \mathrm{E}\right)$. The advantage of micro-propagated plantlets is genetically homogeneous and disease-free; in this study, to minimize differences in growth responses between plants caused by genetic factors, the plantlets were propagated from a mother plant. The shoots were cultured on MS (Murashige and Skoog) medium without plant growth regulators for root formation for 15 days before transferring to the acclimatization stage. The plantlets preparation protocol was briefly described in the Supplemental Information, Figure S1. The acclimation was conducted in a PFAL from June 27 to July 27, 2018, and environmental conditions were set up at a photosynthetic photon flux density (PPFD) of $150 \mu \mathrm{mol} \mathrm{m}^{-2} \mathrm{~s}^{-1}$, a photoperiod of $12 \mathrm{~h}, \mathrm{a} \mathrm{CO}_{2}$ concentration of $1,200 \mu \mathrm{mol} \mathrm{mol}^{-1}$, a relative humidity of $50 \% \pm 10 \%$, and a temperature of $23^{\circ} \mathrm{C}$. The plantlets were placed in a sowing tray $(30 \mathrm{~cm}$ wide, $60 \mathrm{~cm}$ long, $4 \mathrm{~cm}$ deep) that contained 1.5 L Hoagland and Arnon's (1950) nutrient solution modified the same as mentioned below. The solution was adjusted to electrical conductivity of $1.2 \mathrm{mS} \mathrm{cm}^{-1}$ with $\mathrm{pH} 6.0$ for the young plantlets.

In SPF, the strawberry plantlets were grown on vertical shelves, and nutrient solution was distributed by a circulation system. A pump (45 L min-1, $70 \mathrm{~W}$; Iwaki Co., Ltd.) was used to supply the nutrient solution continuously from a container to the cultivation shelves; these shelves were connected to each other and to the container by supply pipes. The nutrient solution was a modification of Hoagland and Arnon's (1950) solution containing $3 \mathrm{mM} \mathrm{Ca}\left(\mathrm{NO}_{3}\right)_{2}, 2 \mathrm{mM}$ $\mathrm{KNO}_{3}, 2 \mathrm{mM} \mathrm{KH}_{2} \mathrm{PO}_{4}, 2 \mathrm{mM} \mathrm{MgSO}_{4}, 25 \mu \mathrm{M} \mathrm{H}_{3} \mathrm{BO}_{3}, 6 \mu \mathrm{M} \mathrm{MnSO}_{4}$, $2 \mu \mathrm{M} \mathrm{ZnSO}_{4}, 0.5 \mu \mathrm{M} \mathrm{CuSO}_{4}, 0.5 \mu \mathrm{M} \mathrm{Na}_{2} \mathrm{MoO}_{4}$, and $0.1 \mathrm{mM}$ Fe-EDTA. This solution had an electrical conductivity of $1.8 \mathrm{mS} \mathrm{cm}^{-1}$ with $\mathrm{pH} 6.0$, and was renewed every 2 weeks. The plants were grown under $1,200 \mu \mathrm{mol} \mathrm{mol}{ }^{-1} \mathrm{CO}_{2}$ at a relative humidity of $50 \% \pm 10 \%$ and temperature established at $23^{\circ} \mathrm{C}$. The flowering induction of June-bearing strawberries can be achieved under short-day conditions with temperatures ranging from $15^{\circ} \mathrm{C}$ to less than $25^{\circ} \mathrm{C}$ (Ruan et al., 2011). Besides, in this study, we first focused on examining the effect of light conditions on plant growths at an appropriate temperature. Therefore, the plants were grown under a temperature of $23^{\circ} \mathrm{C}$ without chilling treatments.

In Okinawa, the periods July to October and November to January represent long-day and short-day conditions, respectively (Jiro and Hiroshi, 1987). Therefore, since flower induction in this June-bearing cultivar occurs under shortday conditions, the experiment was conducted from July 28, 2018 to January 10, 2019 to investigate the growth responses of the strawberries in both vegetative and reproductive stages. For more details, the timing of strawberry growth stages was described in Figure 1.

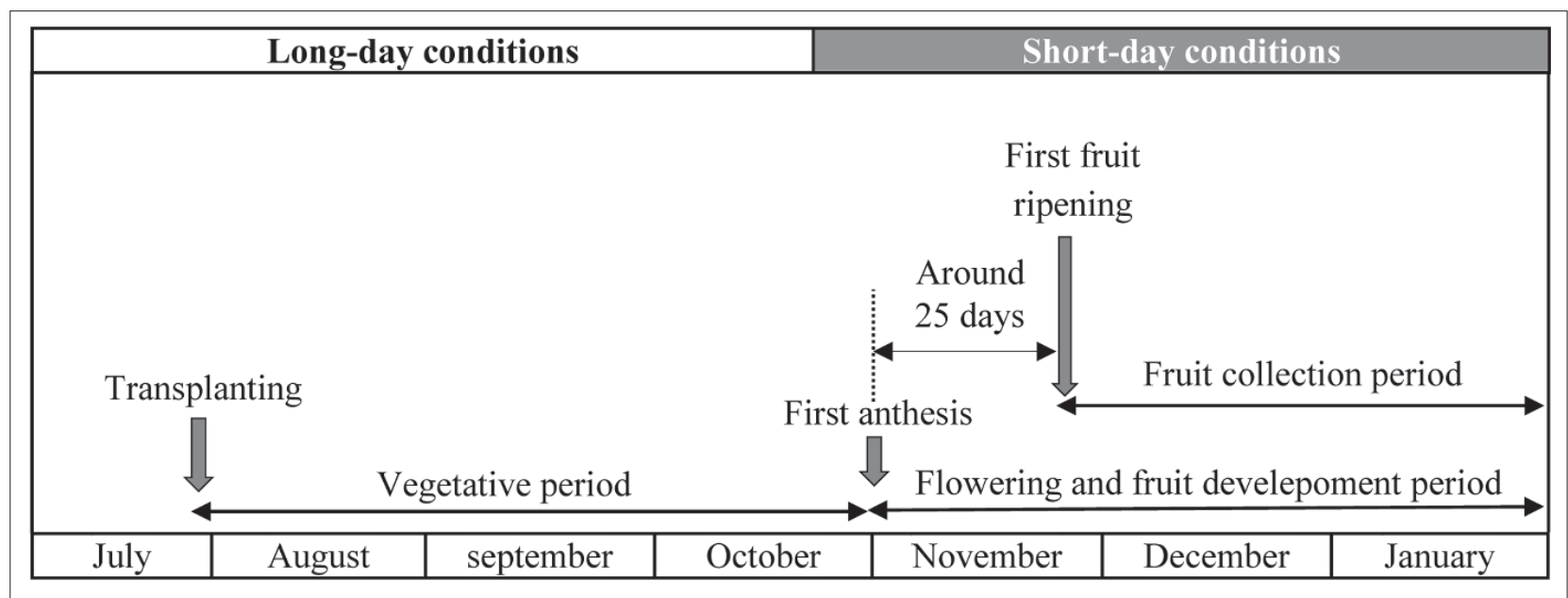

FiguRE 1. Descriptions of the timing of strawberry growth stages in the solar plant factory under long-day and short-day conditions. 

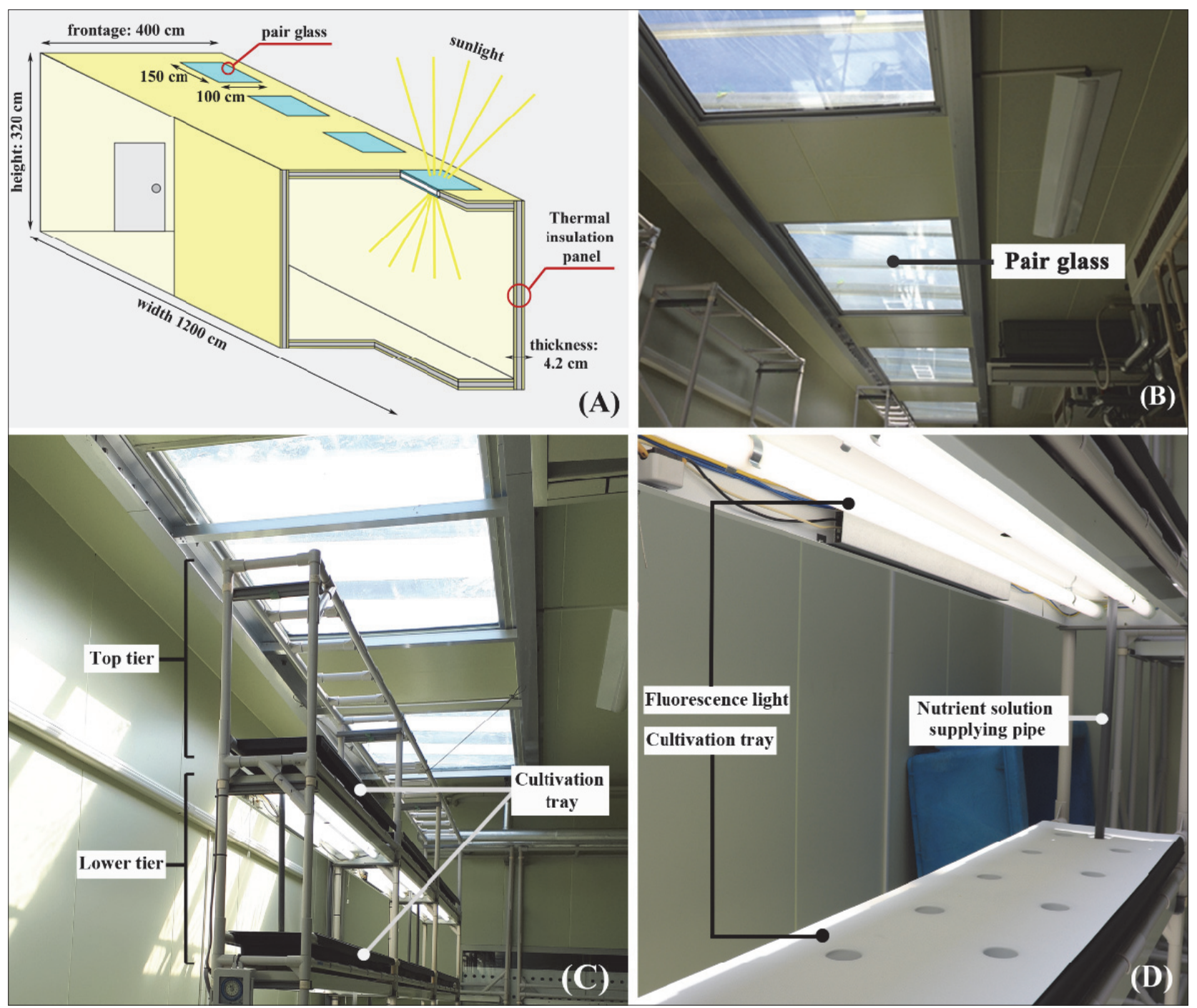

FIGURE 2. Solar plant factory diagram (A); revised rooftop with pair glasses (B); vertical cultivation shelves with the top tier (S, sunlight) and the lower tier (SA, low sunlight and artificial light) (C); and cultivation tray (D).

\section{SPF specifications}

The SPF used in this study was described in detail by Ueno and Kawamitsu (2017). Briefly, a rooftop was modified with a pair of transparent, heat-insulating glass panes $(90 \times 180 \mathrm{~cm}, 3 \mathrm{~mm}$ thick, $70 \%$ solar transmittance rate; Asahi Glass Co. Ltd., Japan) with an air layer of $2 \mathrm{~mm}$ between them. The SPF with a modified rooftop and vertical cultivation system is shown in Figure 2. Cultivation trays (28 $\mathrm{cm}$ wide, $120 \mathrm{~cm}$ long, $7 \mathrm{~cm}$ deep) were placed on the tiers in the SPF to grow plants (Figure 2C, D). The trays on the top tiers were $100 \mathrm{~cm}$ from the heat-insulating glass and exposed to sunlight ( $\mathrm{S}$ treatment). Those on the lower tiers partly received sunlight intensity (approximately $10 \%$ on a sunny day) and were supplemented with fluorescent light using a PPFD of $65 \pm 5 \mu \mathrm{mol} \mathrm{m}{ }^{-2} \mathrm{~s}^{-1}$ (SA treatment). The photoperiod in the SA treatment was controlled to $14 \mathrm{~h} \mathrm{(5:00} \mathrm{am}$ to 7:00 pm) during long-day periods and $10 \mathrm{~h}$ (7:00 am to 5:00 pm) during short-day periods, following the day length in the $S$ treatment. The PPFD in the SA treatment was recorded at the beginning of the experiment on a sunny day (including the supplemented fluorescent light, maximum = $180 \mu \mathrm{mol} \mathrm{m}^{-2} \mathrm{~s}^{-1}$ ) using a LI-250A light meter (LI-COR, Inc., U.S.A.).

\section{Experimental design}

The strawberry plants were exposed to two different light treatments: sunlight only (S) and low sunlight + fluorescent light (SA). In the S treatment, light intensity completely relies on the sunlight introduced in the SPF. The SA treatment was designed in order to simulate the low light conditions (Figure 2C, D). The supplemented fluorescent light is to maintain a stable low light intensity of this treatment at a base of $65 \pm 5 \mu \mathrm{mol} \mathrm{m} \mathrm{m}^{-2} \mathrm{~s}^{-1}$ against sunlight fluctuation at a low level in short-day conditions. The experiment was performed in triplicates with four plants per treatment in each replicate.

\section{Gas exchange measurement}

Photosynthesis was measured using the third fully expanded leaves from the tops of the plants. The net photosynthetic rate $\left(\mathrm{P}_{\mathrm{n}}\right)$ was measured using a portable photosynthesis system (Li-6400; Li-COR, Lincoln, Nebraska, U.S.A.), with a flow rate of $300 \mu \mathrm{mol} \mathrm{s}^{-1}$, an atmospheric $\mathrm{CO}_{2}$ concentration of $1,200 \mu \mathrm{mol} \mathrm{mol}{ }^{-1}$, and a block temperature of $25^{\circ} \mathrm{C}$. The plants were first exposed to the highest PPFD of 2,000 $\mu \mathrm{mol}$ $\mathrm{m}^{-2} \mathrm{~s}^{-1}$, followed by progressively lower intensities of 1,600 , $1,200,800,400,150,50$, and $0 \mu \mathrm{mol} \mathrm{m}^{-2} \mathrm{~s}^{-1}$. Photosynthetic measurements were performed twice in the vegetative [49 
days after transplanting (DAT) under long-day conditions] and reproductive (154 DAT under short-day conditions) stages.

\section{Data collection}

Experimental data collection was divided into the vegetative and reproductive growth stages. Vegetative response was investigated only during the long-day period. Vegetative growth parameters such as the leaf number, shoot number, and SPAD values were collected every 4 weeks. The SPAD values, of the $4^{\text {th }}$ wide-open leaves from the top of the plants, were measured using a SPAD meter (SPAD-502; Minolta, Japan). The reproductive growth parameters were collected during the short-day period (December to January) and included the flower number, inflorescence number, and fruit developmental parameters (weight, length, and diameter). The harvested fruits were sorted into three categories by weight (type I: $0-5 \mathrm{~g}$; type II: 5-10 g; and type III: $>10 \mathrm{~g}$ ), and the percentage of each fruit type was determined by calculat- ing the ratio of the fruit number of a particular type to the total number of fruits harvested in each treatment.

The light intensity and temperature in the SPF were recorded every 10 min during the experimental period using a TR-74Ui illuminance UV recorder (T\&D Corporation, Japan) that was placed on the top or lower tier of the cultivation shelf, and light intensities during the photosynthetic measurement processes were automatically recorded by the Li6400 portable photosynthesis system.

\section{Flower pollination}

We applied manual pollination to strawberry flowers instead of the use of bees because bees can pose some risks (namely, fungus and bacteria that are carried by bees or develop on bee dead bodies) to the sanitary environments inside the plant factory (Hiroshi, 2019). The flowers were pollinated manually using a small paintbrush. The pollens from the stamens were brushed over the stigmas of the fully open flowers.

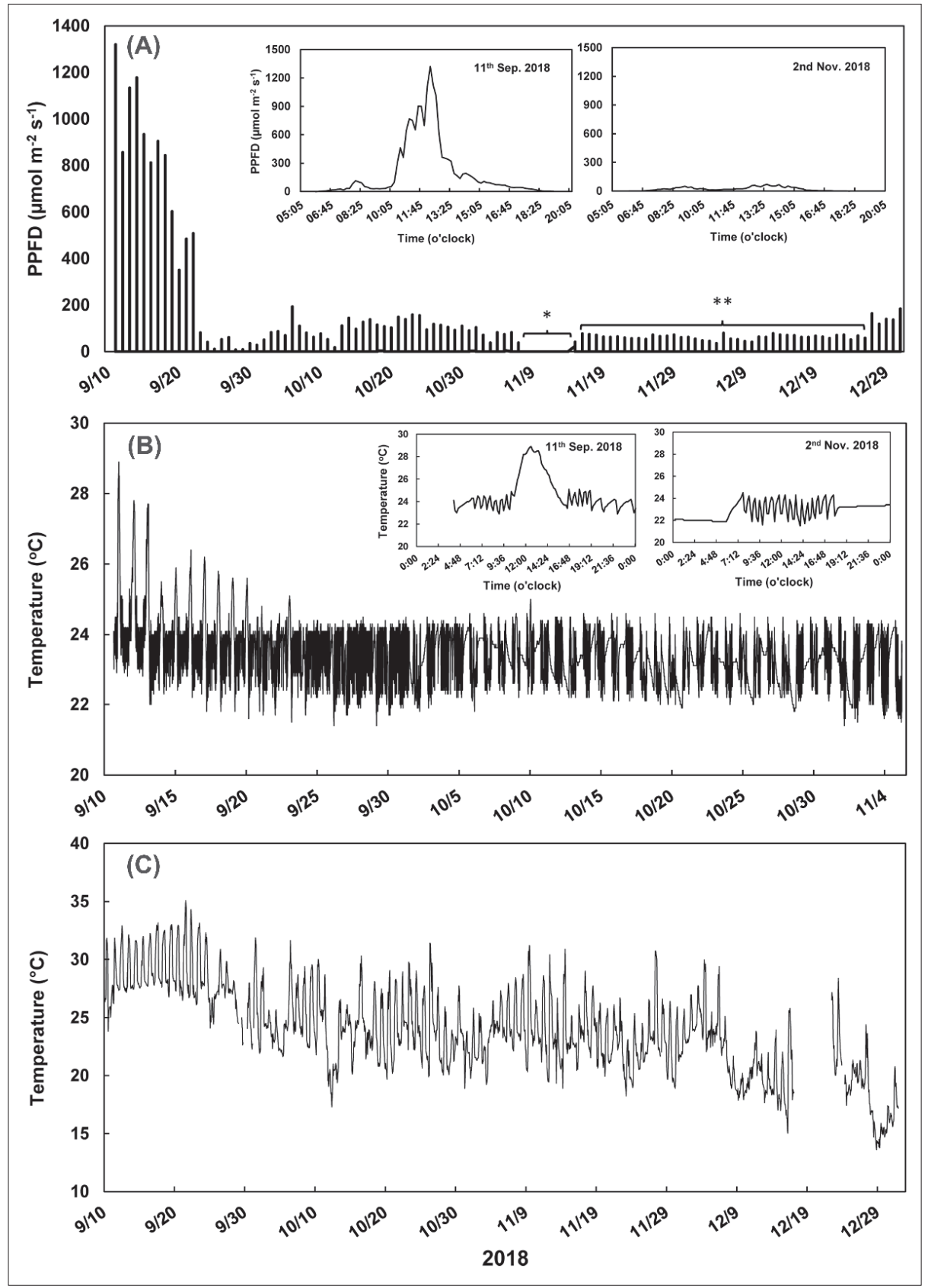

FIGURE 3. Sunlight intensity in $S$ treatment $(A)$ and air temperature (B) in solar plant factory, air temperature outside the plant factory (C); lost data $(*)$, data collected on SA treatment $(* *)$. 


\section{Statistical analysis}

The mean and standard error of each parameter were calculated for each treatment and they were compared between treatments using Student's $t$-test. All analyses were performed in Excel 2016 using a significance level of $\mathrm{P}<0.05$.

\section{Results and discussion}

\section{Light conditions in the SPF}

Variation in sunlight intensity in the SPF differed among the long- and short-day periods (Figure 3A). Under long-day conditions, the light intensity varied over a wide range of $0-1,400 \mu \mathrm{mol} \mathrm{m}^{-2} \mathrm{~s}^{-1}$ with the $\mathrm{S}$ treatment and over a narrower range of $0-180 \mu \mathrm{mol} \mathrm{m}^{-2} \mathrm{~s}^{-1}$ with the SA treatment. In contrast, under short-day conditions, the light intensity varied over a smaller range for both $\mathrm{S}\left(0-200 \mu \mathrm{mol} \mathrm{m}^{-2} \mathrm{~s}^{-1}\right)$ and SA $\left(0-80 \mu \mathrm{mol} \mathrm{m}^{-2} \mathrm{~s}^{-1}\right)$ treatments. The results in Figure 4C, D showed that fluctuations of sunlight intensity in photoperiod at $S$ treatment could occur at very low levels $(20-60 \mu \mathrm{mol}$ $\mathrm{m}^{-2} \mathrm{~s}^{-1}$ ) when cloudy. Meanwhile, the supplementary light revealed a positive effect on the light intensity in SA treatment. It was more stable and maintained at a higher level (55-80 $\mu \mathrm{mol} \mathrm{m}{ }^{-2} \mathrm{~s}^{-1}$ ) in the short-day conditions. From such fluctuating light characteristics, we realized that introducing sunlight to PFAL has two main issues that need attention. First was the seasonal fluctuation, which tended to decrease sharply in the short-day conditions, or in winter (often cloudy and rainy). The second was light fluctuation and at very low intensity in the short-day conditions. The evaluation of plant growth responses and reproductive ability under such lighting conditions are discussed in the following sections.

In this experiment, we did not focus on the temperature variation; however, there might be queries about the chang- es in temperature when introducing sunlight in a PFAL. The thermal information is mentioned in this section to confirm that there were no harmful effects from the temperature. Under long-day conditions, the air temperature inside the SPF fluctuated from $22^{\circ} \mathrm{C}$ during the nighttime to $29^{\circ} \mathrm{C}$ during the daytime. However, under short-day conditions, the air temperature remained more stable, fluctuating from $22^{\circ} \mathrm{C}$ during the nighttime to $24^{\circ} \mathrm{C}$ during the daytime. The air conditioner in the SPF was set to $23^{\circ} \mathrm{C}$ to prevent high temperatures during high solar radiation outside the plant factory. Notably, from 11:00 am to 3:00 pm in September, the average temperature in the $\mathrm{SPF}$ was $24.6^{\circ} \mathrm{C}$, which was approximately $6^{\circ} \mathrm{C}$ lower than the average ambient temperature outside the plant factory $\left(30.7^{\circ} \mathrm{C}\right.$ ) (Figure $3 \mathrm{~B}, \mathrm{C}$ ). Thus, while the temperature inside the SPF was not perfectly controlled to $23^{\circ} \mathrm{C}$ during this time, it was maintained within an acceptable range $\left(22-29^{\circ} \mathrm{C}\right)$ to prevent any negative effects on the photosynthesis and growth of the strawberry plants. Kadir and Sidhu (2006), and Carlen et al. (2009) previously demonstrated that the photosynthesis of strawberry was inhibited at a temperature of $40^{\circ} \mathrm{C}$, with $30^{\circ} \mathrm{C}$ being optimal for $\mathrm{P}_{\mathrm{n}}$ and vegetative growth.

\section{Leaf traits and photosynthetic profile}

The strawberry plants increased leaf number during the cultivation period from August to October, reaching a maximum in October irrespective of the light conditions (Table 1). The leaf number was significantly lower under the SA treatment than with the $\mathrm{S}$ treatment at all times. The shoot number of the strawberry plants increased with the S treatment but remained at a low level with the SA treatment during the cultivation period (Table 1). This result showed that the vegetative growth response of strawberries in SPF was as
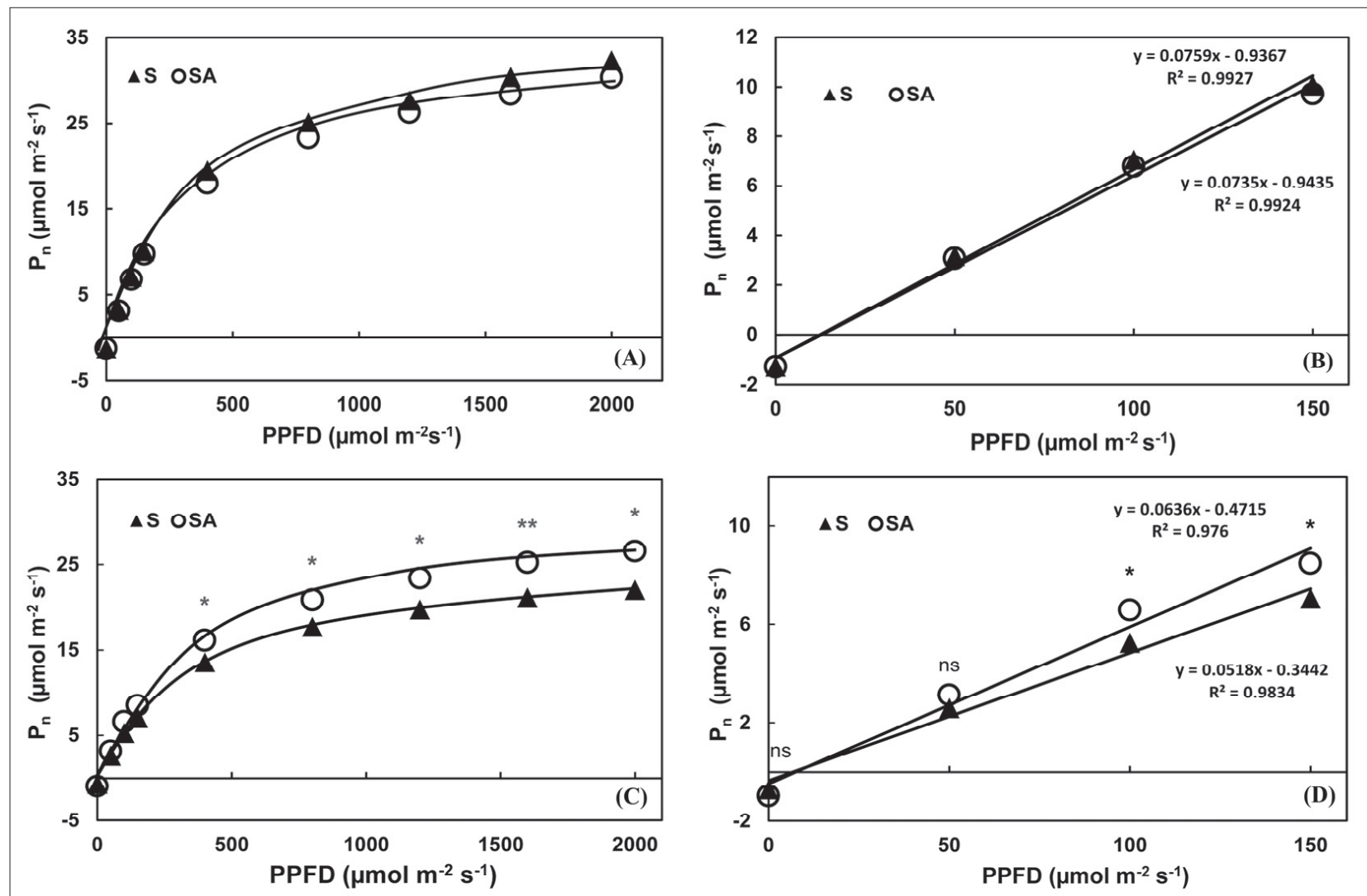

FIGURE 4. Ambient light intensity during photosynthetic measurement process in S treatment in long-day (A) and short-day conditions (B), and in SA treatments in long-day (C) and short-day conditions (D). 
TABLE 1. Leaf number, crown number and SPAD value of strawberry under SPF conditions (means \pm standard error).

\begin{tabular}{|c|c|c|c|c|c|c|c|c|c|}
\hline \multirow{2}{*}{ Treatment } & \multicolumn{3}{|c|}{ Leaf number plant $^{-1}$} & \multicolumn{3}{|c|}{ Crown number plant ${ }^{-1}$} & \multicolumn{3}{|c|}{ Leaf SPAD value } \\
\hline & Aug. & Sep. & Oct. & Aug. & Sep. & Oct. & Aug. & Sep. & Oct. \\
\hline$S$ & $9.3 \pm 1.2^{*}$ & $21.4 \pm 1.6^{*}$ & $28 \pm 1.8^{*}$ & $1.9 \pm 0.9^{n s}$ & $2.3 \pm 0.7^{n s}$ & $3.1 \pm 0.8^{*}$ & $37.7 \pm 1.6^{n s}$ & $39.9 \pm 1.3^{n s}$ & $38.2 \pm 1.6^{n s}$ \\
\hline SA & $6.6 \pm 0.9$ & $14.6 \pm 1.9$ & $18 \pm 1.7$ & $1.4 \pm 0.7$ & $1.9 \pm 0.9$ & $1.8 \pm 0.7$ & $38.8 \pm 1.6$ & $41.2 \pm 1.3$ & $38.6 \pm 1.5$ \\
\hline
\end{tabular}

$S$ or SA denotes plant grown under full sunlight or under low sunlight + fluorescence light.

${ }^{*},{ }^{n s}$ indicates significant difference, non-significant difference at $P<0.05$ by $t$-test, respectively.

normal as other plants; most plants have an increase in the leaf numbers, shoot numbers and their biomass when grown under high light intensity (Yao et al., 2017; Feng et al., 2019; Aspinall and Paleg, 1964). Moreover, this result also revealed clearly the potential of leveraging sunlight into the PFAL to promote the growth of strawberry plants.

Under long-day conditions, there was no significant difference between the $S$ and SA treatments with respect to the light response curves of the strawberry leaves measured at PPFD values of $0-2,000 \mu \mathrm{mol} \mathrm{m}^{-2} \mathrm{~s}^{-1}$ (Figure 5A, B). This result indicated that light variation in the range of $60-1,400$ $\mu \mathrm{mol} \mathrm{m} \mathrm{m}^{-2} \mathrm{~s}^{-1}$ did not limit the photosynthetic ability of the strawberries grown in SPF. The strawberry plants grown under a low-light intensity in the SA treatment had a similar photosynthetic ability to plants grown under full sunlight in the $S$ treatment indicated that low-light intensity $(60-180$ $\mu \mathrm{mol} \mathrm{m}{ }^{-2} \mathrm{~s}^{-1}$ ) conditions had no adverse effect on the physiology of the strawberry leaves. Besides, the normal physiological condition of leaves is also expressed through SPAD value, which is one of the criteria to evaluate chlorophyll content in leaves and to reflect the biochemical status of leaves (Guer and Ozcelik, 2007). In our results, SPAD values were relatively constant with both treatments regardless of low or high light conditions (Table 1). Furthermore, at PPFDs of 2,000 $\mu \mathrm{mol} \mathrm{m}{ }^{-2} \mathrm{~s}^{-1}$, the maximum $\mathrm{P}_{\mathrm{n}}$ values in both $\mathrm{S}$ and $\mathrm{SA}$ treatments were approximately $32 \mu \mathrm{mol} \mathrm{m}^{-2} \mathrm{~s}^{-1}$, which are not inferior to the usual $P_{n}$ values of strawberry plants growing in a $\mathrm{CO}_{2}$-enriched greenhouse (Hidaka et al., 2016).

Under short-day conditions, the $\mathrm{P}_{\mathrm{n}}$ values of the strawberry leaves were lower than those measured under longday conditions in both S and SA treatments (Figure 5A, C). However, the photosynthetic ability and the initial slope of the light response curve of the strawberry leaves were significantly higher with the SA treatment than with the $S$ treatment $(0.0636, r=0.988 ; 0.0518, r=0.992$ ) (Figure 5C, D). In combination with data presented in Figure 5B and D, these results make it clear that in short-day conditions, the light fluctuation combined with low intensity in the SPF were the main reasons that led to reducing the photosynthetic ability of the strawberries. Vialet-Chabrand et al. (2017) dem-

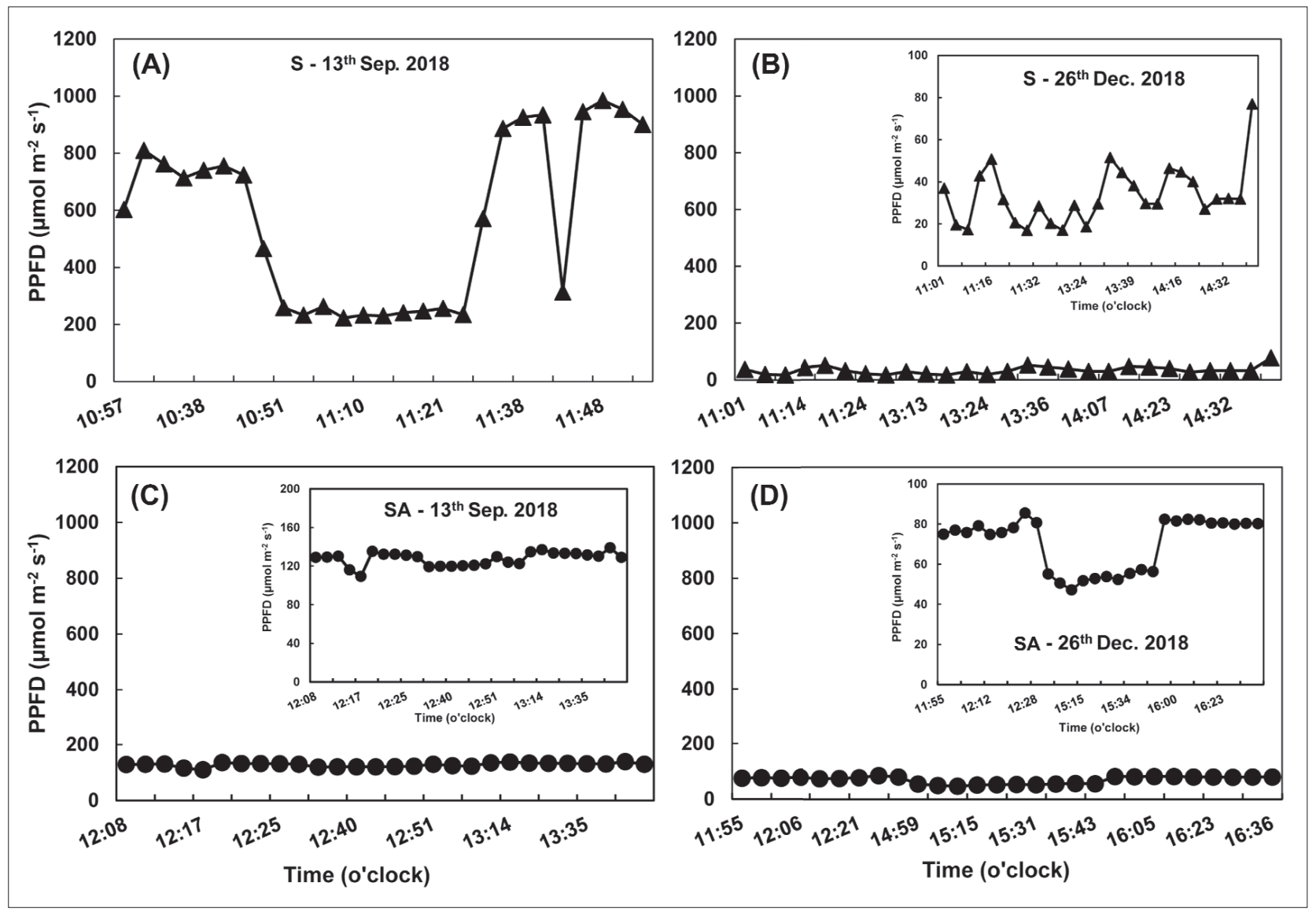

FIGURE 5. Net photosynthetic rate (A) and initial slope (B) in long-day conditions, net photosynthetic rate (C) and initial slope (D) in short-day conditions. ns, ${ }^{*}, *$ denote non-significant, significant at $\mathrm{P}<0.05$ or $\mathrm{P}<0.01$, respectively (means data compared by $t$-test). 
TABLE 2. Number of flower (no. flowers), inflorescence (no. inflorescences), fruit (no. fruit) per plant, and percentage of fruit type of strawberry grown in SPF (means \pm standard error).

\begin{tabular}{|c|c|c|c|c|c|c|}
\hline \multirow{2}{*}{ Treatment } & \multirow{2}{*}{$\begin{array}{l}\text { No. flowers } \\
\text { plant }^{-1}\end{array}$} & \multirow{2}{*}{$\begin{array}{l}\text { No. inflorescences } \\
\text { plant }^{-1}\end{array}$} & \multirow{2}{*}{$\begin{array}{l}\text { No. fruit } \\
\text { plant }^{-1}\end{array}$} & \multicolumn{3}{|c|}{ Percentage of fruit type (\%) } \\
\hline & & & & Type I (<5 g) & Type I (>5 g) & Type I (>10 g) \\
\hline$S$ & $21.5 \pm 0.8^{*}$ & $3.7 \pm 0.2^{*}$ & $6.8 \pm 0.3^{*}$ & 45.0 & 45.0 & 10.0 \\
\hline SA & $17.8 \pm 0.8$ & $2.2 \pm 0.1$ & $3.1 \pm 0.2$ & - & 54.2 & 45.8 \\
\hline
\end{tabular}

$S$ or SA denotes plant grown under full sunlight of under low sunlight + fluorescence light.

* indicates significant difference at $\mathrm{P}<0.05$ by $t$-test, respectively.

TABLE 3. Fruit weight and fruit size of strawberry under different light conditions in SPF (means \pm SE).

\begin{tabular}{lccccccccc}
\hline & \multicolumn{3}{c}{ Fruit type I $(<5 \mathrm{~g})$} & \multicolumn{3}{c}{ Fruit type I $(>5 \mathrm{~g})$} & \multicolumn{3}{c}{ Fruit type I $(>10 \mathrm{~g})$} \\
\cline { 2 - 9 } Treatment & $\begin{array}{c}\text { Weight } \\
(\mathrm{g})\end{array}$ & $\begin{array}{c}\text { Length } \\
(\mathrm{cm})\end{array}$ & $\begin{array}{c}\text { Diameter } \\
(\mathrm{cm})\end{array}$ & $\begin{array}{c}\text { Weight } \\
(\mathrm{g})\end{array}$ & $\begin{array}{c}\text { Length } \\
(\mathrm{cm})\end{array}$ & $\begin{array}{c}\text { Diameter } \\
(\mathrm{cm})\end{array}$ & $\begin{array}{c}\text { Weight } \\
(\mathrm{g})\end{array}$ & $\begin{array}{c}\text { Length } \\
(\mathrm{cm})\end{array}$ & $\begin{array}{c}\text { Diameter } \\
(\mathrm{cm})\end{array}$ \\
\hline $\mathrm{S}$ & $3.7 \pm 0.2$ & $2.9 \pm 0.6$ & $1.9 \pm 0.7$ & $6.0 \pm 0.4^{\text {ns }}$ & $3.4 \pm 0.6^{n s}$ & $2.6 \pm 0.6^{n s}$ & $10.9 \pm 0.8^{\text {ns }}$ & $3.6 \pm 0.8^{\text {ns }}$ & $2.9 \pm 0.7^{\text {ns }}$ \\
SA & - & - & - & $7.2 \pm 0.4$ & $3.3 \pm 0.1$ & $2.4 \pm 0.2$ & $12.4 \pm 0.4$ & $3.8 \pm 0.1$ & $3.1 \pm 0.1$ \\
\hline
\end{tabular}

$S$ or SA denotes plant grown under full sunlight of under low sunlight + fluorescence light.

${ }_{n s}$ indicates significant difference, non-significant difference at $P<0.05$ by $t$-test, respectively.

onstrated that plants reduced their photosynthetic ability when grown under fluctuating light intensity compared to those grown under stable light conditions. Therefore, the maintenance of light stability even at low intensity (55-80 $\mu \mathrm{mol} \mathrm{m}{ }^{-2} \mathrm{~s}^{-1}$ ), such as in the SA treatment, showed a positive effect on improving the photosynthesis ability of the strawberries (Figure 5C, D). Thus, the supplemented lighting to maintain the stability of light intensity could overcome the disadvantage of fluctuation and low light intensity in shortday conditions in SPF.

\section{Reproductive growth traits}

The strawberry plants in the SPF bloomed and set fruits regardless of the light conditions. Hidaka et al. (2016) reported that strawberry plants grown in a greenhouse under elevated $\mathrm{CO}_{2}$ produced 14.2 and 21.8 flowers per plant under non-supplemental and supplemental lighting, respectively. However, we found that the use of full sunlight or a low sunlight intensity supplemented with fluorescent light resulted in high flower numbers ranging from 17.8 to 21.5 flowers per plant (Table 2), thus indicating that plants that were grown in the SPF had similar reproductive abilities to those under controlled environmental greenhouse conditions. A higher photosynthesis activity combined with the strong growth in leaf and shoot numbers under the effect of high light intensity enhanced reproductive traits (Smeets, 1980; Goto et al., 2018), which induced the production of significantly higher numbers of inflorescences, flowers, and fruit in $\mathrm{S}$ treatment than those in the SA treatment (Tables 1, 2).

The size and weight of the harvested fruits were similar for the two light conditions. However, plants in the SA treatment did not produce any type I fruit, and produced a higher proportion of type II $(54.2 \%)$ than type III (45.8\%) fruit. Plants in the $\mathrm{S}$ treatment produced equal proportions of type I and II fruits (45\% each) and a much lower proportion of type III fruits (10\%). The number of fruits per strawberry plant was low (3.1-6.8 fruit plant ${ }^{-1}$ ) despite the high flower numbers (Table 2). This low fruit set may have resulted from the low efficiency of manual pollination, which may have led to the significant difference in fruit numbers between the two treatments. It is also possible that a plant with a large number of fruits would experience less fruit size enlargement than a plant with a smaller number of fruits. This is reflected by the fact that plants in the $\mathrm{S}$ treatment produced twice as many fruits as those in the SA treatment group but had a lower proportion of type III fruits (Table 2).

Interestingly, the plants grown in the $\mathrm{S}$ treatment showed superiorities in vegetative and reproductive growths compared with that in the SA treatment. It indicates the efficiency of using sunlight in SPF. Wang and Wang (2014) agreed that higher light intensity from full sunlight conditions enhances photosynthesis and vegetative growth, specifically in leaf area, which results in better reproductive growth. Similarly, previous studies reported negative effects of shading on strawberry growth under greenhouse and field conditions. The lower light intensity due to shading leads to the reductions in leaf number, crown number, and the subsequent reduction in the flower number, fruit number, and smaller fruit sizes compared with those grown under full sunlight (Awang and Atherton, 1995; Demirsoy et al., 2007; Wang and Wang, 2014). In this study, high light intensity along with long photoperiod could give advantages on vegetative growth with better leaf number, crown number, and SPAD values, which potential for higher reproductive growth in flower number, fruit number in S treatment. In the opposite way, more stable and higher light intensity during short-day conditions since supplemental lighting in SA treatment could give advance in the higher percentage of the fruit type of bigger size (Table 2). In order to ensure better plant growth, continuous and year-round production, the supplemental lighting during the short-day conditions, and increasing the light intensity in the lower tiers should be required.

\section{Conclusion}

When sunlight is applied in a closed-type plant factory, it is important that both the light intensity and its fluctuation have to be considered, as each of these could affect crop growth responses and variate markedly between seasons. Under long-day conditions, the photosynthetic ability of the strawberry plants was not affected significantly by the light conditions in SPF; however, the growth parameters measured were greater under the full sunlight condition, which contributed to an increased fruit productivity in terms of the numbers of inflorescences, flowers, and fruits. In contrast, the low and fluctuating light intensity that occurred under short-day conditions reduced the photosynthetic ability of 
the strawberry plants. The strawberry plants in SPF showed a high potential to produce flowers and fruits, which were not inferior to those under other controlled environment productions. To address the issue of fluctuation and lowlight intensity under short-day conditions in the SPF and allow the year-round cultivation of strawberry in the tropics or subtropics, the supplemental lighting to maintain the stability of light intensity is recommended. Therefore, strawberry production using SPF is practicable in the subtropics. Some treatments for flowering induction may be considered in the long-day condition to advantageously use sunlight to promote the growth of flowers and fruits. The effects of other factors on the productivity of the strawberry plants in the SPF, such as mineral nutrition or pollination methods, were not considered in the present study and should be investigated in the future.

\section{References}

Aspinall, D., and Paleg, L.G. (1964). Effects of day length and light intensity on growth of barley. III. Vegetative development. Australian J. Biol. Sci. 17, 807-822. https://doi.org/10.1071/BI9640807.

Awang, Y.B., and Atherton, J.G. (1995). Growth and fruiting responses of strawberry plants grown on rockwool to shading and salinity. Sci. Hortic. 62, 25-31. https://doi.org/10.1016/0304-4238(95)00770-T.

Carlen, C., Potel, A.M., and Ançay, A. (2009). Photosynthetic response of strawberry leaves to changing temperatures. Acta Hortic. 838, 73-76. https://doi.org/10.17660/ActaHortic.2009.838.11.

Choi, H.G., Moon, B.Y., and Kang, N.J. (2016). Correlation between strawberry (Fragaria ananassa Duch.) productivity and photosynthesis-related parameters under various growth conditions. Front. Plant Sci. 7, 1607. https://doi.org/10.3389/ fpls.2016.01607.

Demirsoy, L., Demirsoy, H., Uzun, S., and Öztürk, A. (2007). The effects of different periods of shading on growth and yield in 'Sweet Charlie' strawberry. Eur. J. Hortic. Sci. 72, 26-31.

Feng, L., Raza, M.A., Li, Z., Chen, Y., Khalid, M.H.B., Du, J., Liu, W., Wu, X., Song, C., Yu, L., et al. (2019). The influence of light intensity and leaf movement on photosynthesis characteristics and carbon balance of soybean. Front. Plant Sci. 9, 1952. https://doi.org/10.3389/ fpls.2018.01952.

Giampieri, F., Forbes-Hernandez, T.Y., Gasparrini, M., Alvarez-Suarez, J.M., Afrin, S., Bompadre, S., Quiles, J.L., Mezzettia, B., and Battino, M. (2015). Strawberry as a health promoter: An evidence based review. Food Funct. 6, 1386-1398. https://doi.org/10.1039/C5F000147A.

Goto, N., Honma, Y., Yusa, M., Sugeno, W., Iwasaki, Y., Suzuki, H., Yoneda, T., Hikosaka, S., Isigami, Y., and Goto, E. (2018). Effects of using LED supplementary lighting to improve photosynthesis on growth and yield of strawberry forcing culture. Acta Hortic. 1227, 563-570. https://doi.org/10.17660/ActaHortic.2018.1227.71.

Guer, S., and Ozcelik, H. (2007). Relationships between leaf chlorophyll and yield related characters of dry bean (Phaseolus vulgaris L.). Asian J. Plant Sci. 6, 700-703. https://doi.org/10.3923/ ajps.2007.700.703.

Hidaka, K., Dan, K., Imamura, H., Miyoshi, Y., Takayama, T., Sameshima, K., Kitano, M., and Okimura, M. (2013). Effect of supplemental lighting from different light sources on growth and yield of strawberry. Environm. Control Biol. 51, 41-47. https://doi. org/10.2525/ecb.51.41.

Hidaka, K., Dan, K., Imamura, H., Miyoshi, Y., Takayama, T., Kitano, M., Sameshima, K., and Okimura, M. (2016). Twofold increase in strawberry productivity by integration of environmental control and movable beds in a large-scale greenhouse. Environm. Control Biol. 54, 79-92. https://doi.org/10.2525/ecb.54.79.
Hiroshi, S. (2019). Advanced technologies for pollination in plant factories. In Plant Factory Using Artificial Light, M. Anpo, H. Fukuda, and T. Wada, eds. (Oxford: Elsevier), p. 185-192. https://doi. org/10.1016/B978-0-12-813973-8.00018-X.

Hoagland, D.R., and Arnon, D.I. (1950). The water-culture method for growing plants without soil. Calif. Agric. Experim. Station, Circular $347,30-32$.

Jiro, A., and Hiroshi, N. (1987). Evaluation of winged bean in Okinawa. JARQ 21, 146-152.

Kadir, S., and Sidhu G. (2006). Strawberry (Fragaria $\times$ ananassa Duch.) growth and productivity as affected by temperature. HortScience 41, 1423-1430. https://doi.org/10.21273/HORTSCI.41.6.1423.

Kawasaki, S., Uehara, N., Tokeshi, M., Kawamitsu, Y., and Ueno, M. (2015). Development of the cultivation system with the variable light source distance to plants with sliding shelf. JSAM 75, 355-362 (in Japanese).

Kozai, T. (2013). Resource use efficiency of closed plant production system with artificial light: Concept, estimation and application to plant factory. Proc. Japan. Acad., Ser. 89, 447-461. https://doi. org/10.2183/pjab.89.447.

Kozai, T., and Niu G. (2016). Plant factory as a resource-efficient closed plant production system. In Plant Factory, T. Kozai, G. Niu, and M. Takagaki, eds. (London: Academic Press), p. 69-90. https://doi. org/10.1016/B978-0-12-801775-3.00004-4.

Nakamura, K., and Shimizu, H. (2019). Plant factories in Japan. In Plant Factory Using Artificial Light, M. Anpo, H. Fukuda, and T. Wada, eds. (Oxford: Elsevier), p. 319-325. https://doi.org/10.1016/B9780-12-813973-8.00028-2.

Ruan, J., Lee, Y.H., Yeoung, Y.R., and Larson, K.D. (2011). Influence of short day treatment on autumn fruit production of June-bearing strawberry cultivars. Hortic. Environm. Biotechnol. 52, 259-264. https://doi.org/10.1007/s13580-011-0001-3.

Simpson, D. (2018). The economic importance of strawberry crops. In The Genomes of Rosaceous Berries and Their Wild Relatives, T. Hytönen, J. Graham, and R. Harrison, eds. (Springer Int. Publishing AG, part of Springer Nature), p. 1-7. https://doi.org/10.1007/9783-319-76020-9_1.

Smeets, L. (1980). Effect of the light intensity on forcing of the strawberry cultivar 'Glasa'. Sci. Hortic. 13, 33-35. https://doi. org/10.1016/0304-4238(80)90019-9.

Ueno, M., and Kawamitsu, Y. (2017). Design of a plant factory suitable for Okinawa. Eng. Appl. Sci. Res. 44, 182-188.

Upmeyer, D.J., and Koller, H.R. (1972). Diurnal trends in net photosynthetic rate and carbohydrate levels of soybean leaves. Plant Physiol. 51, 871-874. https://doi.org/10.1104/pp.51.5.871.

Vialet-Chabrand, S., Matthews, J.S.A., Simkin, A.J., Raines, C.A., and Lawson, T. (2017). Importance of fluctuations in light on plant photosynthetic acclimation. Plant Physiol. 173, 2163-2179. https:// doi.org/10.1104/pp.16.01767.

Wang, J., and Wang, H. (2014). Effects of shade on strawberries in hydroponic cultivation. Acta Hortic. 1049, 733-736. https://doi. org/10.17660/ActaHortic.2014.1049.114.

Yao, X., Liu, X., Xu, Z., and Jiao, X. (2017). Effects of light intensity on leaf microstructure and growth of rape seedlings cultivated under a combination of red and blue LEDs. J. Integr. Agric. 16, 97-105. https://doi.org/10.1016/S2095-3119(16)61393-X.

Received: Jan. 10, 2020

Accepted: Jun. 15, 2020 
Addresses of authors:

Lu Trong Le ${ }^{1,2}$, Hoang Thai Dinh ${ }^{3}$, Hiroo Takaragawa ${ }^{1}$,

Kenta Watanabe ${ }^{1}$, Kenji Ureshino ${ }^{1}$ and

Yoshinobu Kawamitsu',*

${ }^{1}$ Faculty of Agriculture, University of the Ryukyus, Okinawa

903-0213, Japan

2 The United Graduate School of Agricultural Science,

Kagoshima University, Kagoshima 890-8580, Japan

${ }^{3}$ Faculty of Agronomy, Vietnam National University of

Agriculture, Hanoi 131000, Vietnam

* Corresponding author;

E-mail: kawamitu@agr.u-ryukyu.ac.jp

Tel.: +81.98-895-8754; Fax: +81.98-895-8734

\section{SUPPLEMENTAL INFORMATION}

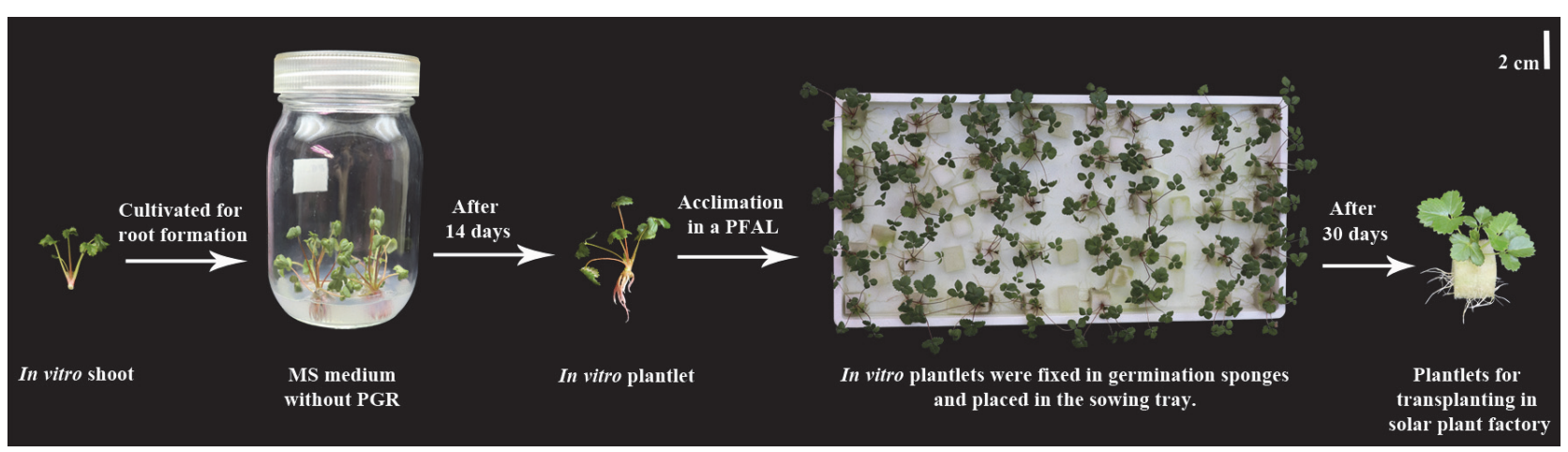

SUPPLEMENTAL INFORMATION - FIGURE S1. Strawberry plantlets preparation protocol. Conditions of cultivation for root formation: MS medium without PGR, PPFD of $65 \mu \mathrm{mol} \mathrm{m}{ }^{-2} \mathrm{~s}^{-1}$, photoperiod of $12 \mathrm{~h}$, temperature of $24^{\circ} \mathrm{C}$. The acclimation conditions: PPFD of $150 \mu \mathrm{mol} \mathrm{m}^{-2} \mathrm{~s}^{-1}$, photoperiod of $12 \mathrm{~h}, \mathrm{CO}_{2}$ concentration of $1,200 \mu \mathrm{mol} \mathrm{mol}^{-1}$, relative humidity of $50 \% \pm$ $10 \%$, temperature of $23^{\circ} \mathrm{C}$, and nutrient solution of Hoagland and Arnon's (1950) (modified) with electrical conductivity of 1.2 $\mathrm{mS} \mathrm{cm}{ }^{-1}$. MS medium: Murashige and Skoog's medium used for plant tissue culture, PGR: plant growth regulator, sowing tray size: $30 \mathrm{~cm}$ wide, $60 \mathrm{~cm}$ long, $4 \mathrm{~cm}$ deep (in the Figure, the $2 \mathrm{~cm}$ bar could not be used for estimating the real dimension of the sowing tray). 